\title{
La puerta en el muro
}

\author{
Pedro Luis Barcia \\ Profesor emérito, Facultad de Comunicación, Universidad Austral \\ pedrolbarcia@gmail.com \\ DOI: https://doi.org/10.26422/aucom.2020.0902.bar
}

El comunismo es la revolución más la electricidad. Lenin (pre McLuhan)

Agradezco a los directores de Austral Comunicación la generosidad cordial de poner mi nombre en la marquesina de neón electrónico de su acreditada revista. Antes de que esta decisión se revierta, me apresuro a destinarles mis dos discursos de reconocimiento, el breve "Gracias" y el extenso "Muchísimas gracias".

Sin intenciones de comenzar con Noé, quiero sí remontarme a los comienzos de nuestra Facultad de Comunicación, cuando abrimos, simultáneamente -esto fue un paso con las botas de las siete leguas-, la Licenciatura y el Doctorado en la materia, este, el primero en el país. Se hizo una selección de docentes para el plantel del primer año de la Licenciatura. El tribunal encargado de ello estaba constituido por tres autoridades del campo comunicacional que, a diferencia de la tríada mítica del Hades -Minos, Eaco y Radamanto-, nos citaba a la vida y no al tránsito final. ${ }^{1}$ Me propusieron asumir la asignatura "Literatura Universal" del flamante plan de estudios y consultaron mi opinión. Estimé que no tenía funcionalidad una materia así para una carrera como la que se iniciaba allí y que su contenido se asemejaría a una guía telefónica por lo extenso de las constancias nominales de autores y obras, dado el menudo lapso que debía cubrir de 4200 años, tentativamente, y que, en su lugar, yo propondría otra cátedra. Y uno de los jueces picó y operó de Lucanor al preguntarme: “¿E cómo se faría eso?”, lo que me dio el esperado pie para proponer la que denominaríamos "Contenidos Culturales Contemporáneos" y que la muchachada llama "Cececé".

El lector (si todavía está ahí) se preguntará a qué viene esto de comenzar ab ovo. Viene a pelo (no "al pelo", como decimos los argentinos), pues esta cátedra es la primera del primer año cuando los alumnos ingresan. Es la recepción. Tiene un "valor de posición", como dicen los estructuralistas. Se entra a la Comunicación por la Cultura. Y, se sabe, que es clave la puerta de acceso por la que se comienza la excursión de un edificio. Ese sitio vestibular exigía en egipcios, etruscos y griegos un baño lustral, con todo lo

Una advertencia: desde el mito ya se daban casos de nepotismo que amañaban resultados electivos: Radamanto era hermano de Minos. 
Pedro Luis Barcia

La puerta en el muro

que de iniciación esa inmersión implica. ${ }^{2}$ Lessing dice que nadie pasea impunemente bajo la sombra de las palmeras, ella nos influye, cuanto más que esa excursión cultural supone el encuentro con Kafka, Hemingway, Ionesco, Picasso, los grandes directores de cine, los pensadores actuales, el Huxley de Un mundo feliz y el Orwell de 1984, y así parecidamente. Y lo peculiar de nuestro programa es que, partiendo de Borges, se salmonea hacia Homero, y de Marechal hacia Sófocles, de lo actual hacia los mitos fundacionales de Occidente. Y desarrolla las edades de la cultura en los marcos de la logosfera, la grafosfera, la inconosfera y sus estadios.

Y nuestro estudiante, como el Lionel Wallace protagonista del cuento de H. G. Wells “La puerta en el muro", una vez que descubrió el jardín deslumbrante, buscará el retorno a él en una revisita. A mitad de su caminar "por la calle gris de Westkensington, halló el muro blanco y en él la puerta verde..... El muchacho franqueó esa puerta y tuvo su deslumbramiento personal. Esa incursión le dejará la apetencia al regreso, la nostalgia de lo vivido. Eso es lo que aporta el jardín de la cultura visitada a tiempo.

Con los años -señalo un segundo hito destacable en nuestro intento e interés de asociar cultura y comunicación-, publicamos No seamos ingenuos. Manual para la lectura inteligente de los medios, ${ }^{3}$ con el lema del labriego que le contestó a Giner de los Ríos sobre cómo trabajaban tan ordenadamente el campo: "Todo lo que sabemos lo sabemos entre todos". En esa obra, los profesores de los distintos lenguajes comunicativos analizamos las incidencias que ellos tenían en la conformidad del hombre y su cultura, los efectos peculiares y diferenciados de su retórica. El libro fue pontonero entre los dos ámbitos.

$\mathrm{Y}$, finalmente, la tercera estación de este periplo es que ese texto colectivo pudo ser la base para un seminario ${ }^{4}$ que asumió la asignatura "La educación tecnológica", en la orientación que a este sintagma le diera Neil Postman en El fin de la educación. ${ }^{5}$

Dividamos las aguas del campo tecnológico a la luz de nuestro interés. De un flanco tenemos todos los recursos técnicos de la comunicación desde la gestualidad y la oralidad al celular, y, por otro, los efectos de esa tecnología en el hombre, en sus aptitudes y actitudes y en los productos culturales que él genera. Entiendo por "cultura" la despejada definición de Ortega: "El conjunto de soluciones que una comunidad da a los problemas básicos de su existencia”: la comunicación, la economía, la educación, el gobierno político, la religión, la política, las diversiones, etc. Se insiste con firmeza en

\footnotetext{
El profesor que esto escribe era mero ostiario, orden menor que en la Edad Media cumplían en los conventos quienes franqueaban la puerta a los visitantes, y la función era habitualmente desempeñada por el hermano lego inepto para otras labores.

3 Barcia, P. L. (Coord.). (2008). No seamos ingenuos. Manual para la lectura inteligente de los medios. Buenos Aires: Santillana.

4 Llamo "seminario" al instrumento poderoso de comunicación universitaria inventado por los alemanes en el siglo XVIII, y no a los hoy así nominados: triviales encuentros cuniculares que envilecen el nombre que exhiben.

Postman, Neil. El fin de la educación. Barcelona, Octaedro, 1995, Cap. 9.
} 
la necesidad de conocer los mecanismos de los medios tecnológicos comunicativos, su manejo diestro y provechoso. Y está bien. Pero se insiste menos en el estudio de los efectos y modificaciones que sobre el hombre ejercen dichos elementos técnicos. A este enfoque es al que Postman denomina "educación tecnológica", no a "la alfabetización tecnológica". La educación tecnológica se constituye en una verdadera asignatura humanística que estudia las avenidas de doble mano entre ambos términos: cultura y comunicación. Sobre esta problemática, sabemos, abunda una aluvial bibliografía, pero interesa que toda facultad de Comunicación la seleccione -cernidor en mano- y organice esa cátedra o seminario hacia el fin de la carrera, en cuyo programa se desarrollen explícitamente "las relaciones peligrosas" y activas mencionadas, a la luz de que toda tecnología es moneda de dos caras: nos sirve y nos condiciona, y cobra su peaje por cada concesión que nos brinda. El saber en qué nos modifica o afecta es el principio del señorío sobre la técnica, porque el sábado está hecho para el hombre y no a la inversa, Biblia dixit. 